\title{
Detection of suitable zooplankton from three taxonomic groups for application in biomanipulation
}

\author{
N. K. Wickramasinghe and S. K. Yatigammana* \\ Department of Zoology, Faculty of Science, University of Peradeniya, Peradeniya, Sri Lanka
}

\begin{abstract}
Many lentic water bodies of the world are under the threat of cultural eutrophication and experience problems associated with algal blooms. Biomanipulation is a useful technique applied to control algal blooms by deliberate alteration of an ecosystem through addition and removal of organisms. The feeding behavior of zooplankton has been applied in biomanipulation in controlling algal densities and to accelerate ecosystem recovery. For this, it is important to select the most efficient filter feeders. The present experiment was carried out to assess the grazing ability of five different zooplankton species belonging to three taxonomic groups, Cladocera, Copepoda and Ostracoda. Filtering efficiency of each algal species by selected zooplankton species were assessed by counting algal cells in each zooplankton introduced systems. Specific growth rate was calculated using the equation $\left(\ln \mathrm{N}_{1}-\ln \mathrm{N}_{0}\right) /\left(\mathrm{t}_{1}-\mathrm{t}_{0}\right)$ where, $\mathrm{N}_{0}($ cells $/ \mu \mathrm{l})$ and $\mathrm{N}_{1}$ (cells $/ \mu \mathrm{l}$ ) are cell counts at times $\mathrm{t}_{0}$ (day) and $\mathrm{t}_{1}$ (day) respectively. The results indicated that zooplankton used in the experiment possess varied capacities of grazing on different species of algae. Chlorella sp. was well controlled by Ceriodaphnia cornuta whereas Crucigenia sp. was controlled better with the Stenocypris sp. Although species of Scenedesmus are favored by many zoopklankton as a food, it was better controlled by the members of the group Ostracoda and also by $C$. cornuta. Even though Monoraphidium sp. was controlled better by all the study species of zooplankton, $C$. cornuta showed the highest performances followed by ostracods.
\end{abstract}

Keywords: Eutrophic lentic systems, algal blooms, feeding behaviour.

\section{INTRODUCTION}

Surface waters, both lotic and lentic systems, experience algal blooms during trophic upsurge. High algal biomass in lentic freshwater systems including lakes and reservoirs commonly results from eutrophication mainly due to the loading of nutrients (Mustapha, 2009). Even though algae are necessary and beneficial to aquatic ecosystems, providing food and energy for nearly all other aquatic organisms, elevated levels of algal growth may negatively affect the health of aquatic systems. Further, nuisance algal blooms decrease aesthetic value of aquatic systems by reducing water clarity, creating unpleasant taste and odor. Extremely high levels of algae can make enough shade to prevent sunlight from reaching submerged aquatic macrophytes, limiting their growth or even causing their disappearance.

Nutrient enrichment in aquatic systems is a major cause for high algal biomass and now there is a considerable concern on this issue as it affects not only aquatic organisms but terrestrial organisms, including humans (Carpenter et al., 1985; Smith, 1982). A classic traditional limnological approach in controlling algae is to understand lake ecosystem structure which orient at the food-chain concept and go through each trophic level: 1) nutrients, 2) phytoplankton, 3) zooplankton and 4) fish. Nevertheless, fish as top carnivores were not thoroughly considered as a component which may efficiently affect waterquality (Rigler, 1982). However, the use of biomanipulation as a tool for water management started in 1970's in small lakes and was later applied to large lakes due to the success of application (Lammens, 2001). Biomanipulation or biological restoration is seen as an option for restoring turbid lakes and reservoirs characterized by high phytoplankton biomass often with no aquatic plants to clear water through absorption of nutrients (Mustapha, 2009). Therefore, biomanipulation can be considered as a deliberate exploitation of interactions between the components of an aquatic ecosystem in order to reduce algal biomass (Wright and Shapiro, 1984). This method was introduced as an alternative to nutrient management and may provide a long 
term effectiveness that nutrient management has failed to do in eutrophied lakes. Hence, biomanipulation is typically used in lakes that are small, shallow, and closed systems and it is likely to be the most successful in controlling algae in shallow eutrophic lakes (Mustapha, 2009). Further, it appears to produce desirable results in many applications. Unfortunately, the success in some cases can be limited and short term, thus further research is necessary to enhance the stability of biomanipulation (Shapiro, 1995). Therefore, a laboratory experiment was conducted to select the most suitable zooplankton from three selected groups for potential applications in biomanipulation.

\section{MATERIALS AND METHODS}

\section{Collection of samples and culturing of species}

For the collection of both phytoplanktons and zooplanktons, 20 reservoirs were selected to represent the three major climatic regions of Sri Lanka (Figure 1). Phytoplanktons were collected using plankton nets with $34 \mu \mathrm{m}$ and $70 \mu \mathrm{m}$ pore sizes, and $100 \mu \mathrm{m}$ pore size was used to collect zooplankton. Each sample was preserved in $4^{\circ} \mathrm{C}$ and was brought to the environmental research laboratory of the Department of Zoology, University of Peradeniya Sri Lanka for culturing (Zooplankton sampling protocol, 2011).

The plate culturing of algae was done to obtain pure cultures. Bold's Basal Medium (BBM) was used for the plate culturing. An amount of $200 \mathrm{ml}$ was taken from the culture media and $2.00 \mathrm{~g}$ of agar was added to the medium separately. The culturing media and other glassware were autoclaved under the pressure of $15 \mathrm{psi}$ and temperature of $121^{\circ} \mathrm{C}$ for about 15-20 minutes. Then the autoclaved culture medium was transferred into petri dishes under sterile conditions and plates were covered until the agar medium solidified. Then each water sample from 20 reservoirs was diluted to the 10-3 dilution factor. An amount of $100 \mu \mathrm{l}$ was taken from each water sample and was transferred into each solidified culture medium. Then the samples were spread with sterilized glass spreader. The culture plates were sealed with parafilm and allowed to incubate for 15-20 days under ambient temperature and light intensities. Then the pure cultures were isolated and used in the experiment. Five species of phytoplankton which are highly abundant in the reservoirs showing relatively high growth rates were selected for the experiment, Chlorella sp., Crucigenia sp. Scenedesmus dimorphus, Scenedesmus quadricauda and Monoraphidium sp. Then the pure cultures were established following a standard dilution procedure by Anderson and Kawachi (2005). These five species proved to be relatively common in natural waters and easy to rear under laboratory conditions (Elliott et al., 2006; Millie et al.,1992; Lurling and Roessink, 2006; Moisander et al., 2003).

Cultivation of microalgae to understand the filtering capacity of each zooplankton was carried out using cow dung as the main nutrient source following the method outlined by Vaikosen et al. (2007). In this method, water samples from each reservoir were autoclaved and used as the media. Six grams of cow dung was autoclaved and $500 \mathrm{ml}$ of boiling water was added into 3L glass containers. Then 2,000 $\mathrm{ml}$ of distilled water was added to the containers before covering them with mosquito nets. The containers were allowed to settle for one week.

A total of thirty containers were prepared for the experiment. After a week, $10 \mathrm{ml}$ of the pure cultures (parent cultures) of each phytoplankton species were added to each container. For each phytoplankton species, six containers were prepared, leaving one as a control. These containers were kept for about 15 days under ambient temperature and light intensities to obtain mature and well established cultures of algae from each selected algal species. Before the introduction of zooplankton, algal counts were taken to estimate their initial cell densities.

Selection of zooplankton for the experiment was conducted by considering their multiplication rate, microhabitat in the natural environment as well as in the microcosm. Accordingly, five species of zooplankton which lead mainly planktonic life were selected including two Cladocera (Ceriodaphnia cornuta, Diaphanosoma sp.), two ostracoda (Stenocypris sp., Notodromus sp.) and one Copepoda (Cyclpos sp.). 


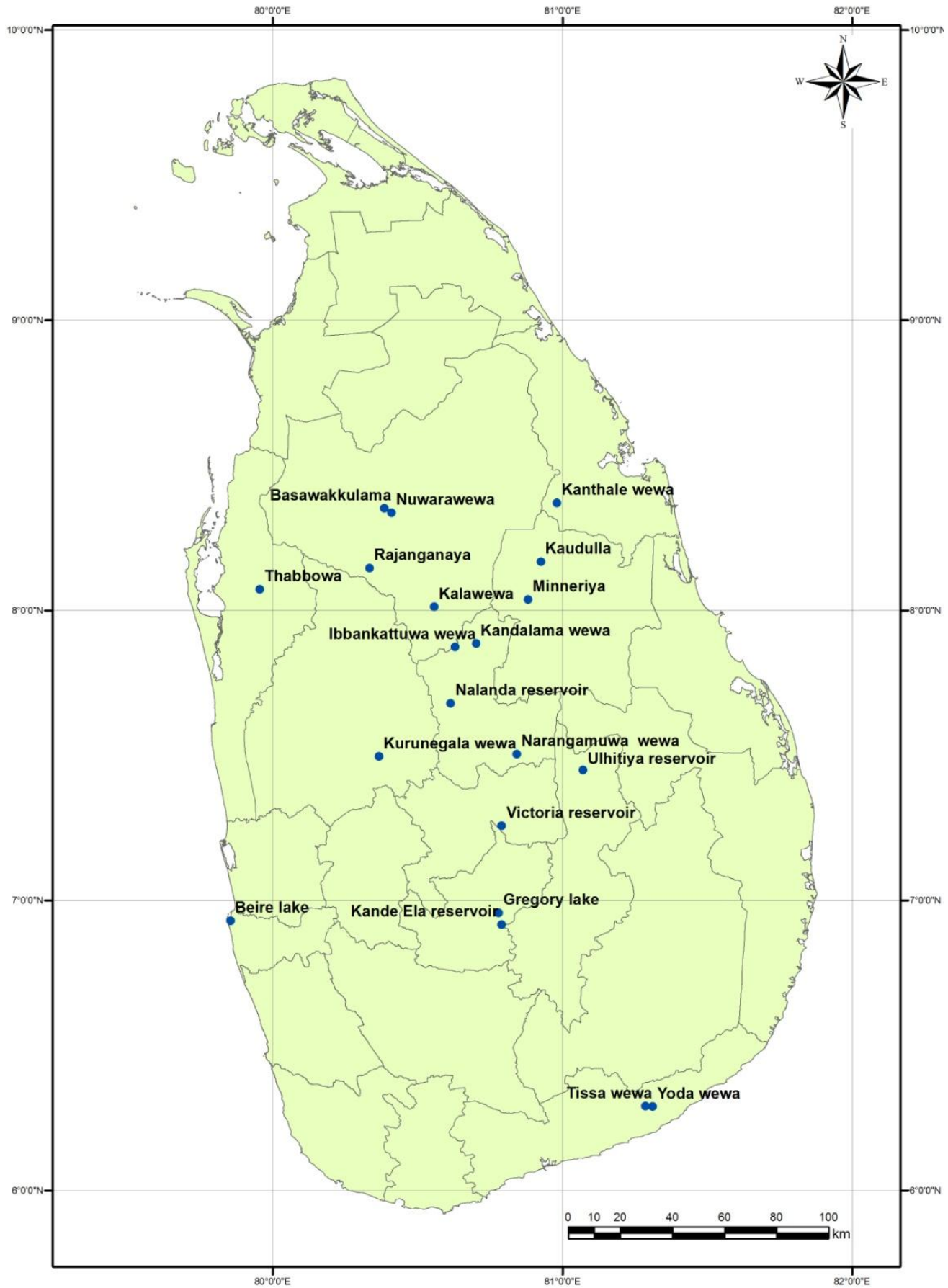

Figure 1: Locations of the 20 reservoirs in Sri Lanka that used to collect samples. 


\begin{abstract}
Introduction of zooplankton to the experimental setup

To each series of algae, five species of zooplanktons were introduced. Each container included one species of algae and one species of zooplankton. The containers maintained as the control included a single species of algae without introduction of any zooplankton species. Steps were taken to assure no contaminations. Thirty individuals from each zooplankton species were isolated and introduced to each container with algae.
\end{abstract}

\section{Monitoring of the performances of each zooplankton species}

After the introduction of zooplankton, the changes of cell density in each algal series were monitored to understand the filtering capacity of different zooplankton. The algal cell counts were taken every week for a period of three months using a Sedgewick rafter cell (PYSER - SGI Limited, United Kingdom). A research microscope (Carl Zeiss, GmbH, Konigsallee, 921 , Germany) was used for the identification and counting of algal cells. Data were analyzed using Microsoft Excel (v. 2010). The specific growth rate of each algal species was calculated using the method explained by Lim ( 2006).

\section{Data Analysis}

The performances of each zooplankton species on controlling of algal densities were analyzed by correlation analysis using Microsoft Excel (v.2010) and by calculating specific growth rates. Specific growth rate $=\left(\operatorname{lnN}_{1}-\operatorname{lnN}_{0}\right) /\left(\mathrm{t}_{1}-\mathrm{t}_{0}\right)$ where, $\mathrm{N}_{0}$ (cells $\left./ \mu \mathrm{l}\right)$ and $\mathrm{N}_{1}$ (cells $\left./ \mu \mathrm{l}\right)$ are cell counts at times $t_{0}$ (day) and $t_{1}$ (day). Specific growth rate of each algae with different zooplankton were compared to understand the filtering capacity of each zooplankton used in the experiment (Figure $3)$.

\section{RESULTS \\ Growth pattern of the five algae species in control systems}

The result of the experiment shows that the algae used in the study exhibits similar growth trends where the density of all five species of algae increased with the time. However, the initial cell density was different in each algal species, having the highest number in Monoraphidium sp. and the lowest number in Crucigenia sp. (Figure 4).

\section{Growth patterns of five species of algae in the presence of different zooplankton species}

When consider the growth rate of each algal species, Chlorella sp. showed a gradual increase of cells with time compared to other species used in the experiment (Figure 4a). However, in the presence of zooplankton it is clear that the normal growth pattern of each algal species was disturbed, and showed a sharp decline of algal cells especially after the second week (Figure 4b). This situation was common to all the algal species used in the experiment. Interestingly, after the $3^{\text {rd }}$ week, the density of algae appears to increase and after $4^{\text {th }}$ week algal density started to decline again except in the presence of Stenocypris sp. This may be due to the ability of zooplankton to starve until they get used to the new type of food available in the system. After the $10^{\text {th }}$ week, the density of Chlorella sp. was steady and completely controlled by the zooplanktons used in the experiment (Figure 4). When consider the overall performance of zooplankton in controlling Chlorella sp. the effectiveness of filtering in both the members of Cladocera (Ceriodaphnia cornuta and Diaphanosoma sp.) and Notodromus sp. is remarkable (Figure 2).

The growth of Crucigenia sp. appears to be different when compared to the growth pattern of other species of algae used in the experiment. Density of algae appears to be stable in the presence of Diaphanosoma sp. and after the $2^{\text {nd }}$ week the algal cell number increased at a higher rate. In the presence of zooplankton, the algal cell density started to reduce after the $6^{\text {th }}$ week and at the end of 12 week period the algae appear to be controlled by all the species of zooplankton used. However, the decline of density appears to be species specific and depends on both consumer and the producer. In the presence of Stenocypris sp. it shows a sharp reduction of algal cells after the $2^{\text {nd }}$ week and continues to reduce the density until it reached a threshold level (Figure 4). Among the five species of zooplankton, the highest performance of controlling Crucigenia sp. growth was exhibited by Stenocypris sp. (Figure 3). 

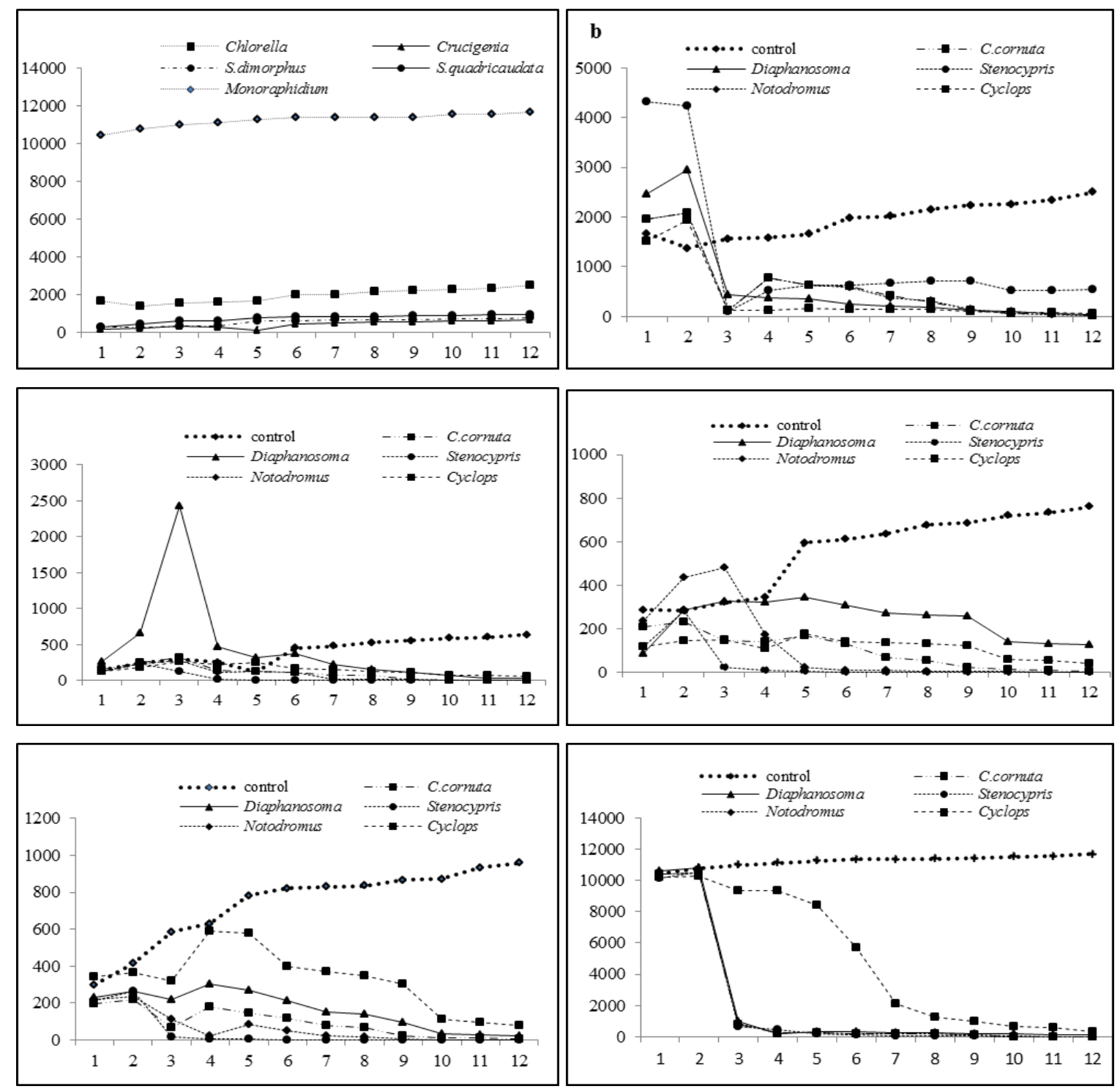

Figure 4: Line graphs showing the differences in growth patterns of algae in control systems (a) and with the presence of five species of zooplankton, Chlorella sp. (b), Crucigenia sp. (c), S.dimorphus (d), S. quadricauda (e), Monoraphidium sp. (f)

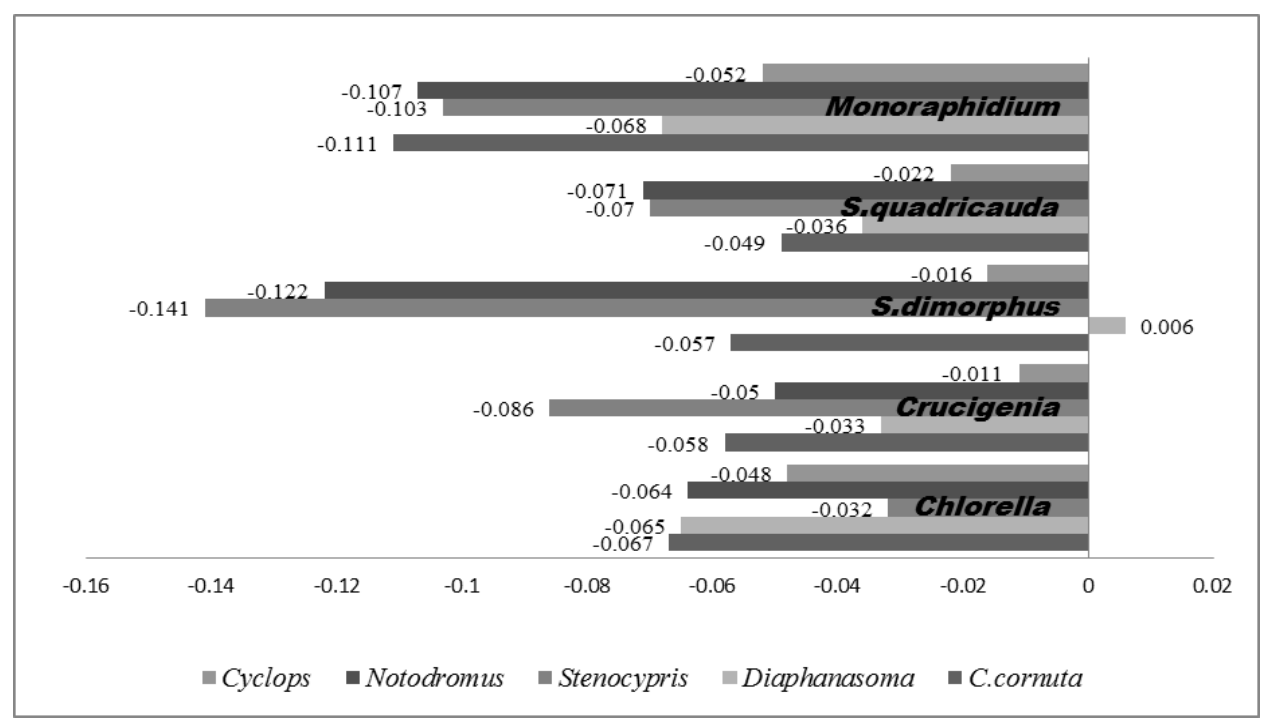

Figure 3: Effectiveness of five selected zooplankton species in controlling five species of algae. 
The growth pattern of $S$. dimorphus was different from other algal species. Although irregularities occur at different intervals, the alga was well controlled by the zooplankton used in the study, especially in the presence of Stenocypris sp., where a complete removal of the alga was observed. In addition, the alga was well controlled by Notodromus sp. after the $6^{\text {th }}$ week of the experiment (Figure 4).

When considering the growth pattern of $S$. quadricauda with other zooplanktons, a rapid reduction was seen after the $6^{\text {th }}$ week. Compared to other species, there was a total reduction of algal cells in the presence of Stenocypris sp. and Notodromus sp. Further, Diaphanosoma sp. and C. cornuta also showed a remarkable filtering ability of S.quadricauda. However, when compared to other species the filtering capacity of Cyclops sp. was low (Figure 4). In the experiment, both species of Scenedesmus were effectively controlled by two species of ostracods than the other zooplankton species used in the experiment (Figure 3).

Unlike the other species of algae, the initial cell density of Monoraphidium sp. was high. In the presence of zooplankton with high filtering capacity, there was a sharp decline of algal cells after the $2^{\text {nd }}$ week. The control of Monoraphidium sp. was almost similar with all the zooplankton species used in the experiment except by Cyclops sp. With the presence of Cyclops sp. the algal cell reduction was gradual (Figure 4). Finally, the best performances of algal control were carried out by C.cornuta and both members of ostracods.

\section{DISCUSSION}

With the increase biomass of algae, several negative effects can be observed especially in natural water bodies. Balanced aquatic systems are characterized by having certain qualities and quantities of biological, chemical and physical components. When the quality and quantities are disturbed, the system becomes imbalance. With the increasing levels of algal biomass, changes could be occurred within the system. It will directly affect the other biological components of the systems by disturbing the food webs and force other species to leave the habitat. Indirectly, it will cause changes in the chemical and then the physical components as well. Mostly this will affect reduction of water quality by reducing the dissolved oxygen level.
Therefore, lake restoration is important where systems have high algal biomasses. This concept can be applied through bottom-up and top-down force. This process can be explained based on which part of an organism's life cycle is being affected. In bottom-up control, it regulates the organism's number due to limited supplies of resources that affects its production of new biomass. In this situation, the nutrients are the responsible component which affects the production of new algal biomass. In top-down control, population regulation can be done through altering the death rates stimulated by predators or herbivores that attack another species or biomass. In this situation, through controlling the zooplankton densities, the phytoplankton biomass can be regulated.

Algal cultivation can be done under variety of environmental conditions but the ideal conditions for higher production of algae need to consider the factors that determine their growth rates and productivity of different algal species or strains (Garofalo, 2009).Therefore, in this experiment, steps were taken to provide essential environmental conditions that allow the algae to grow. According to the results obtained from the experiment, all species of zooplankton selected have the ability to reduce the algal density in different capacities. When simulated systems are considered, in the zooplankton absent systems, all the five species of algae showed an increasing trend of the density indicating that the algae growth is continuous during the period of 12 weeks (Figure 4).

At the beginning of the experiment, Monoraphidium sp. had the highest cell density and Crucigenia sp. had the lowest cell density (Figure 4). Therefore, the present results also agree with Bogen et al. (2013) where a Monoraphidium sp. was identified as an oleaginous species with ability to grow rapidly. Even under nitrogen limited conditions, it composed of predominantly $\mathrm{C} 18: 1$ and C16:0 fatty acids and this could be the reason why Monoraphidium sp. was well filtered by all the zooplankton used in the experiment. In addition, it has been revealed that the Monoraphidium sp. is tolerant to relatively wide $\mathrm{pH}$ ranges and salt concentrations of up to $1.0 \% \mathrm{NaCl}$, in which the cells exhibit larger structures. The surface waters of Sri Lanka contain higher amounts of $\mathrm{Na}$ and $\mathrm{Cl}$ unlike the common scenario of lentic systems of the world (Yatigammana and Cumming, 
2016). Such a change of ionic composition may have helped increas the density and even the size of cells of the species. According to Sterner (1993), biochemical contents of primary producers varied with their growth rate and therefore, herbivores feeding on food with rapid growth rate have different diets than herbivores feeding on low growth rate. Our results indicate that except Cyclops sp. all the other zooplankton used in the experiment showed very rapid filtering capacities and help to reduce Monoraphidium sp. during the first two weeks (Figure 4). Therefore, it is clear that the growth of Monoraphidium sp. can be controlled by all the species used in the experiment. Hence, in the applications of biomanipulation, integrated use of zooplankton may bring better results than the use of single species.

Chlorella sp. is a single-celled green microalgae found in freshwater known as a super food that contains higher nucleic acids (RNA/DNA) than any other food, with an energy producing potential (Yecong et al., 2011). In our experiment, Chlorella sp. showed gradual growth over time during the period of 3 months. However, even with robust growth trend, Chlorella sp. was well controlled by all the zooplankton species used in the experiment (Figure 4). Chlorella sp. has high tolerance to extreme environments, with the ability to grow even in industrial wastes (Kalana et al., 2015). Further, it is used to remove nutrients from the waste water and the biomass is used for biofuel production as it contains high percentage of lipids (Yecong et al., 2011). Unlike other species of algae used in the experiment, Chlorella sp. was well controlled after the third week by all the species of zooplanktons (Figure 4). According to Pipes and Koutsoyannis (1962), the sunlight is a strong environmental factor that limits the growth of Chlorella sp. than any other environmental conditions. In our study, all the steps were taken to provide equal environmental conditions including sunlight for all the cultures of Chlorella sp. Therefore, it is apparent that the growth was controlled by the zooplankton grazers. Among the zooplankton used in the experiment, $C$. cornuta was identified as the most effective zooplankton grazer that control the growth of Chlorella sp. (Figure 3).

Scenedesmus is one of the most common genera of microalgae with diverse applications including biofuel production, wastewater treatment, bio fertilizer, a foliar spray, a seed primer to evaluate seed germination, plant growth, and crop yield for some tomato plants (Gonzalez and Jesus, 2014). However, when they exist as blooms especially in natural systems they could cause both economic and environmental damages. So it has become important to understand the ecology and growth patterns of this important microalga. Consequently, our experiment helps to understand the growth patterns and the control of the species using an environmentally friendly technique. All the zooplankton species used in the experiment were able to control the growth of both Scenedesmus species after the $5^{\text {th }}$ week (Figure 4). However, a variation of filtering by different zooplankton was noticed during the 12 weeks of experimental period. For example, the growth of Scenedesmus dimorphus was controlled better by Stenocypris sp. while in Notodromus sp. system, the cell density of Scenedesmus dimorphus increased initially and after the $3^{\text {rd }}$ week the cell density started to reduce (Figure 4). According to Lürling and Roessink (2006), Scenedesmus species initially inhabit in benthic environment and then disperse to the other areas with the increase of cell density. So the initial increase of cell density of Scenedesmus dimorphus in Notodromus sp. (Ostracoda) system could be related to pattern of colonization of the alga in aquatic systems. Notodromus sp. is an ostracod species that inhabit in the water column. At the initial stage of algal colonization, Notodromus sp. may not be able to control the growth of alga as the habitat of grazer does not overlap with the algal habitat. On the other hand, unlike a large ostracod, Stenocypris sp. and Notodromus sp. are small and therefore the efficiency of filtering may be lower until they establish in the system. Hence, it is apparent why the both ostrcods showed a similar pattern of grazing and filtering of the algae. In addition in Scenedesmuss quadricauda system the grazing pattern of Cyclops sp. was different. After the $3^{\text {rd }}$ week the cell density increased and again it started to reduce (Figure 4). Unlike Scenedesmus dimorphus, Scenedesmus quadricauda is armed with floatation spine. Therefore, the Cyclops sp. may not have been adjusted to feed on the floating individuals initially. However, when compared to the grazing of three types of zooplanktons, cladocera, ostracoda and copepoda, both species of Scenedesmus were well controlled by 
ostracoda species than other two groups (Figure $3)$.

Crucigenia sp. used in the experiment showed a diverse relationship with the tested zooplankton. However, a maximum negative growth rate (-0.086) was demonstrated with Stenocypris sp. and the lowest with Cyclops sp. (-0.011). Even though Crucigenia sp. shows irregularities in growth pattern, after the $6^{\text {th }}$ week all the zooplankton used in the experiment show filtering of Crucigenia sp. to low cell numbers (Figure 4).Unlike other species of algae used in the experiment, Curicigenia sp. appeared to form compacted colonies with several cells. According to the specific growth rates in the systems with ostracod as a grazer showed the highest preference by Stenocypris sp. (Figure 3). In Stenocypris sp., Crucigenia sp. showed a sharp decline of cells in the $4^{\text {th }}$ week (Figure 4). Even Notodromus sp. and C.cornuta reduced the cell number during the same week but the reduction was not as high as with Stenocypris sp. (Figure 4).This situation suggests how the size variations of zooplanktons affect the reduction of cell numbers. Further, specific growth rates suggest that all the species of zooplankton have the ability to control Crucigenia sp. However, as they exhibit some variations depending on their size, it would be encouraging to use larger size zooplanktons to get better results.

\section{CONCLUSION}

According to our study, grazing behaviors of five selected zooplankton species were differed, which could be related to characteristics of algae such as their ecology, morphology and growth characteristics. Benthic and limnetic Scenedesmus sp. was better controlled by the members of the group Ostracoda. C. cornuta, also a good filter feeder, has the potential to control of all algal species especially Chlorella sp. and Monoraphidium sp. The present study shows that the application of zooplanktons can be done with prior selection of their efficiencies in controlling specific algal species.

\section{ACKNOWLEDGEMENTS}

The University grant (Grant number $\mathrm{RG} / 2014 / 42 / \mathrm{S}$ ) is acknowledged for funding the study.

\section{REFERENCES}

Bogen, C., Al-Dilaimi, A., Albersmeier, A., Wichmann, J., Grundmann,M., Rupp, O., Lauersen,K.J.,Klassen,

O.B.,Kalinowski,J.,Goesmann, A.,Mussgnug, S. and Kruse, O. (2013). Reconstruction of the lipid metabolism for the microalga Monoraphidium neglectum from its genome sequence reveals characteristics suitable for biofuel production. BMC genomics.14:926.

Carpenter, S.R., Kitchell, J.F. and Hodgson, J. R. (1985). Cascading trophic interactions and lake productivity. BioScience. 35:634-639.

Elliott, J.A., Jones, I.D. and Thackeray, S.J. (2006). Testing the Sensitivity of Phytoplankton Communities to Changes in Water Temperature and Nutrient Load, in a Temperate Lake. Hydrobiologia. 559: 401-411.

Garofalo, R. (2009). Algae and aquatic biomass for a sustainable production of $2^{\text {nd }}$ generation biofuels . AquaFUELs-Taxonomy, Biology and Biotechnology. 6:1-258.

Gonzalez, G. and Jesus, M.S. (2014). Evaluation of Potential Agricultural Applications of the Microalga Scenedesmus dimorphus. ArizonaStateUniversity: 73.

Kalana, U.L.D.I., Kalpage, C.S. and Yatigammana, S.K. (2015). Assessment of the growth kinetics of selected microalgae species in synthetic wastewater for the production of biodiesel. International Journal of Earth Sciences and Engineering. 8:465-470.

Lammens, E.H.R.R. (2001). Consequences of biomanipulation for fish and fisheries. FAO. Fisheries Circular.952:23-26.

Lim, P., Leaw, C. and Usup, G. (2006). Effects of light and temperature on growth, nitrate uptake, and toxin production of two tropical dinoflagellates: alexandrium tamiyavanichii and alexandrium minutum (dinophyceae). Journal of Phycology.42: 786-799.

Lürling, M. and Roessink, I. (2006). On the way to cyanobacterial blooms: impact of the herbicide metribuzin on the competition between a greenalga (Scenedesmus) and a cyanobacterium (Microcystis).Chemosphere .65:618-626.

Millie, D.F., Baker, M.C., Tucker, C.S., Vinyard, B.T. and Dionigi, C.P. (1992). High- resolution airborne remote sensing of bloom forming phytoplankton. Journal of Phycology.28: 281290.

Moisander, P.H., Steppe, T.F., Hall, N.S., Kuparinen, J. and Paerl, H.W. (2003). Variability in nitrogen and phosphorus limitation for Baltic Sea phytoplankton during nitrogen-fixing cyanobacterial blooms. Marine ecology progress series. 262: 81-95. 
Mustapha, M.K. (2009). Application of biomanipulation in reducing high algal biomass in eutrophicated shallow tropical african reservoirs. American-Eurasian Journal of Sustainable Agriculture. 3:663-666.

Pipes, W.O. and Koutsoyannis, S. P. (1962). Lightlimited growthof Chlorella in continuous cultures. Applied microbiology. 10:1-5.

Rigler, F.H. (1982). The relation between fisheries management and limnology.Transactions of the American Fisheries Society.111:121-132.

Shapiro, J. (1995). Lake restoration by biomanipulation -a personal view. Environmental Reviews. 3:83-93.

Smith, V.H. (1982). The nitrogen and phosphorus dependence of algal biomass in lakes:An empirical and theoretical analysis. Limnology and Oceanography. 27:1101-1112.

Sterner, R. W. (1993). Daphnia growth on varying quality of Scenedesmus : Mineral lmimitation of zooplankton. Ecology.74: 2351-2360.

Vaikosen, S.E., Nwokoro S.O. and Orheruata A.M. (2007). Yield and chemical composition of Chlorella species cultivated in pig, poultry And cow dungs in southern nigeria. ASSET An International journal Series A. 7: 229-235
Victor, R. (2004). Crustacea:Ostracoda. In: C.M. Yule and $\mathrm{H}$. Yong, Freshwater Invertebrates of the Malaysian Region, Academy of Sciences Malaysia Pp.225-233.

Wright, D.I. and Shapiro, J. (1984). Nutrient reduction by biomanipulation : An unexpected phenomenon and its possible cause. Verhandlung International eVereinigung Limnologie. 22.

Yatigammana, S.K. and Cumming, B.F. (2016). Physical and chemical characteristics of ancient and recent reservoirs of Sri Lanka. Fundamental and Applied Limnology. 188: 249-263.

Yecong, L., Chen, Y.F., Chen, P., Min, M., Zhou, W., Martinez, B., Zhu, J. and Ruan, R. (2011). Characterization of amicroalga Chlorella sp. well adapted to highly concentrated municipal wastewater for nutrient removal and biodiesel production. Bioresource technology.102: 51385144.

Zooplankton sampling protocol (2011). Available From:http://www.westernchannelobservatory.org. uk/documents/pmlwco_zooplankton_protocols.pdf/

(29.10.2016). 
